\title{
3. SPECIFICS OF IMPLEMENTATION FORUM THEATRE FOR PEOPLE WITH MILD AND MODERATE MENTAL RETARDATION
}

\begin{abstract}
The paper presents an empirical study in the area of implementation theatre forum for people with mild and moderate mental retardation in an environment of sheltered housing. Forum Theatre already takes place in primary schools, in orphanages, in the Roma community and so on. There is a lack of experience and research studies with the target group of people with intellectual disabilities. The present research was carried out in several phases over a period of one year. The main objective was to determine whether it is possible to use forum theatre techniques and subjects with mild to moderate mental retardation whether this target group will be able to process the theatre forum to engage, understand the meaning and function of these techniques and that these techniques can be used as an alternative remedy to solve the problem and conflict situations. The research sample consisted of 11 adult clients of sheltered housing with mild to moderate mental retardation and 11 members of the realization team of the forum theatre (7 Actors and 4 employees in direct care in sheltered housing). Used qualitative research methods were focus groups (always followed the realization of the theatre workshop forum), participant observation and quantitative method was a questionnaire. Research has brought new insights and information.
\end{abstract} Key words: theatre forum, forum theatre project, mental disability, sheltered housing

\section{Introduction}

"The Theatre is a form of cognition, as well it should and could be a means to transform society. The theatre will help us make our future better than simply waiting for it." (Augusto Boal)

Simultaneous dramaturgy was the predecessor of Forum Theatre. Viewers invent their script and the actors play it simultaneously. Actors played only the ideas and opinions of other spectators, until they were satisfied with the story. Augusto Boal worked with this method until the moment when he had a very unhappy woman with a story replayed in one of his performances in the auditorium. The woman always stopped the storyline and told how she would resolve the situation. Actors played the show again, but the woman was still dissatisfied. So it repeated several times until the emotions of women escalated enough that the women decided to play how she would deal with the situation presented herself. Boal got so interested by this improvisation that he altered the rules and the viewers become co-star. (Chytilová, 2003)

Forum Theatre is the most sophisticated technology of Boal's Theatre of the Oppressed. Actors play the story, which is common for a group of spectators. This story is based on the needs of this group, and should more or less affect each individual. The story is called antimodel which must always end wrong to force the viewer to think about the topic and to have the desire to change something during the show and concerning the audience to be satisfied with the concluding and resolving the situation. This technique is used for various target

\footnotetext{
${ }^{186}$ Assistant Professor Ph.D., "Palacky University" from Olomouc of Czech Republic, email:
} zdenka.kozakova@upol.cz 
groups and in many countries around the world, but its course and the rules are different with different customs. As part of the contribution we have focused on a target group of people with mental disabilities, specifically on clients who use the service of sheltered housing. One of the goals of this service is to develop the abilities, skills and knowledge of clients, as well as the highest possible degree of self-sufficiency and independence from the service. Clients often encounter, in their daily lives, with a variety of stress, crisis, conflict situations, which they do not know how to solve. Therefore, we decided for the experiment, to use Forum Theatre and together with our clients to seek possible solutions to these situations.

\section{Basic Terminology}

Mental retardation - Mental retardation can be defined as a developmental mental disorder with reduced intelligence demonstrated primarily by reducing cognitive, speech, movement and social skills with prenatal, perinatal and postnatal ethology. (Valenta, Kozáková, 2006). Mental retardation is defined as the inability to achieve an appropriate degree for intellectual development, even though the individual was educationally stimulated in acceptable manner. (Vágnerová 2004 in Kozáková, 2013). In terms of the depth of impaired mental retardation, we distinguish between mild, moderate, severe and profound. (Kozáková, 2005)

Theatre Forum of Augusto Boal - the specific name indicating Forum theatre in the form in which it Boal described in his literature, etc. then Newspaper Theatre of Augusto Boal, Image Theatre of Augusto Boal etc. Forum theatre - a generic name, as physical theatre, puppet theatre, drama etc. Scenario of Forum theatre - Boal uses the so called anti-model; this is a performance that, after warm-up, is most often the first part of the workshop and shows the negative end of the story. Forum - mostly the second part of the workshop - performances with spectators' interventions. Forum Theatre workshop - the workshop with participants. Project of Forum theatre addresses the entire process including the preparation, testing, production, Joker preparation, realization of forum theatre workshops and reflection. (Available on the World Wide Web: http: //fedifo.jamu.cz/terminologie.htm,cit.23.10.2015).

\section{Research methodology}

The main objective of the research was to create a project of Forum theatre for people with mild and moderate mental retardation from sheltered housing and to determine by means of implementation whether it is possible to implement Forum theatre technology even to this target group, whether they are able to engage in the process of forum theatre and work with these techniques.

Sub-objectives were to determine:

- Whether the theatre forum could serve as a supportive tool in solving problems and conflict situations of clients with mild to moderate mental retardation,

- Whether the implementation of forum theatre leads to a closer understanding of clients' employees (new knowledge, facts) 
- Whether the forum theatre has space to express their views and attitudes of clients.

\section{Characteristics of the research sample}

- 11 adult clients of sheltered housing with mild and moderate mental retardation aged 25 to 58 years - 7 women and 4 men.

- 11 members of the implementation team, who actively participated in the preparatory and implementation phase of the project - 7 drama students and 4 staff in direct care in sheltered housing.

\section{Methods}

Forum Theatre and then focus groups were held with clients with mental disabilities and with participating observation. Focus groups is such a research technology, which collects data through group interaction resulting in a debate on the topic specified by the host - researcher. Focus is created on the basis of host's interest (depends on the research objectives) so that the researcher marks the focal point and the data are collected through group interaction. Focus groups usually take place between 3-10 debaters with a host who controls the debate and works with group dynamics. As the disadvantage, we can see, the host influence on the creation of themes and group dynamics affecting the views of the participants. Neutrality is ensured by a host. Direct contact of the group can be helpful to unblock the fear and for the mobilization of potential in the group. Civil language allows easy articulation and refinement of needs. It has not been proved that this method was worse than other research methods, e.g. using anonymous questionnaires. (Morgan, 1997) A questionnaire survey was realized with students and staff in direct care.

\section{Forum Theatre project}

Forum Theatre project realized in people with mild to moderate mental retardation was divided into three phases: preparation, implementation and research.

I. Preparatory (i.e. Familiarization) phase included three important steps: Step 1. Familiarization of facilities management and employees of sheltered housing with Forum theatre

In the preparatory phase the project of the Forum theatre (hereinafter FT) was submitted to the director of the facility and then to individual workers of sheltered housing (hereinafter $\mathrm{SH}$ ) who work with the target group of clients. The intended procedures and objectives of the work were described. The new opportunities that may, by the application of FT procedures in the social teaching clients, open and emphasize the expected positive effect (e.g. the possibility of life for clients with less staff support, strengthening the clients' confidence, their personal growth, improvement or interpersonal relationships in the community, developing the ability to solve conflict and stress situations) were outlined. For employees, the information, which briefly explains who A. Boal was, what the philosophy of FT is and which explains the overall intent of the project, has been prepared. Followed by familiarization with specific procedures for working with clients in the project. Because the themes and scenarios should be based on problematic situations of clients' daily life, 
professionals, who work with clients daily, were asked to collaborate on these topics. Valuable suggestions based on years of experience in working with clients arose from the discussion. Many of these ideas were used while editing a project in search for the most common themes of conflict situations that have already occurred or occurs repeatedly. The selected topics were situated to $\mathrm{SH}$ and should take place under "absence" of educators so that clients do not rely on their intervention.

\section{Suggested topics:}

- Fire in SH, alarm went off.

- Turned off electrical current - blown fuse in a storm while watching TV.

- Fake check of the gas meter - an effort to gain money for hours over limit.

- A nagging insurance agent - "Sign the contract, it is favourable!".

- Some client has not cleaned his assigned area in SH and someone else has to do it for him.

- Argument of clients over the bucket when cleaning - the second client cannot clean up and causes conflict with the one who uses the bucket.

- Distaste for fulfilling of the given task - obligation versus voluntary participation in activities. Something is lost - the loss of any personal belongings usually causes instantaneous false accusations. Failure to respect the privacy of other roommates.

- The ability to say no - a situation where one is constantly giving others and they do taking advantage of it and do not offer anything in return.

- Correction of minor malfunctions - e.g. bulbs replacement, clients sometimes act dangerously (trying to fix an electrical appliance with a screwdriver, etc.).

- Sudden nausea of a client in SH. Loss of room keys, home keys.

- Harassment by stranger on the street - e.g. The effort to get personal belongings or client data. Answering the phone in the office staff - the client can talk to the caller, but forgets to pass an important message.

Step 2. Familiarization of clients with mental disabilities with a Forum theatre project

Work on the project with clients of sheltered housing was initiated by informative meeting. A form of presentation that would be understood by all was chosen, regardless the type and degree of their disability. Clients were provided with the possibility of greater independence through involvement in the project and it was explained that it would be only a game, testing different situations that can happen and are usually resolved by the tutor. However, they should be able to cope with these kinds of situations if they want to become independent. The replayed example gave them the idea of the project: "Two friends are sitting in a pub at the table and drink some shots of alcohol when they start to argue, one of them has to pay those two shots. They argue over who whose it is to pay, quarrel escalates, as one slaps the other in the face. "Clients usually respond with laughter, showing their amusement. Clients were asked whether they liked the situation, if both sides have solved it well, whether it was correct to slap one another. 
$\mathrm{H}$.: "That could have not happened at all, everyone could pay for himself and they did not have to argue at all." This client's reaction has provided a good opportunity to demonstrate the meaning of the project. It was explained to clients that in this example, the intention was to show what their mutual cooperation could be like and what the course will be about. At the same time, however, it was emphasized that in these situations we do not have to just talk, it is better to try a different solution directly on the stage. They can contribute with their idea and try to change it, so that the outcome of the situation is satisfying for them.

\section{Step 3. Selecting the actors for the Forum theatre}

A mainstay of successful FT project is the preparation and above all staging of quality professional actors who perform the story. When selecting actors for a production of Forum Theatre, students of Special education and drama at Palacky University in Olomouc, who are actively involved in theatre and at the same time are aware of the Forum theatre, were asked to participate in this project. Students were contacted via email with an attached leaflet informing about the intentions and objectives of the project. Surprisingly, many students responded, but 7 students were selected.

\section{The selection of themes and formation of scenarios}

This was followed by a meeting of the team productions FT (SH employees, students - actors). Meetings were held once a week for 2.5 hours. At these meetings, four themes for staging were selected from the above proposals. When choosing the topics, following criteria were established:

- Topicality of the issue - a selection of frequent conflicts and situations in everyday life of clients

- Technical low demands in theatrical realization - the possibility of adapting the space and equipment and the number of actors who may be involved in the implementation,

- Simplicity and aptness of communication - easily understandable story enables clients to quickly navigate and engage.

\section{By agreement of the whole team was selected following topics:}

1. "BUCKET" or the story of the taken away bucket when cleaning. Ordinary story from the life of clients, which sometimes ends up with aggressive conflict and calling police.

2. "SHARP KNIFE" or how to call the ambulance after being cut with a knife.

3. "BULB" or how repairing a minor malfunction can become life-threatening situation of the client.

4. "DEALER" or how not to be taken in by the statement "Sign the contract, it's favourable".

Subsequently, it was necessary to compose the scenario. First, a working version of which was presented to the whole team was prepared. A discussion followed, which resulted in some additions and changes continuously incorporated into the scenarios. The final form was therefore a work group of the team. At the initial stage it seemed to be the best option. Opinions of the employees were very helpful, because they were based on a thorough 
understanding of client conflict situations in $\mathrm{SH}$ as well on what situations are most difficult for clients, and where, therefore, the project could help the most. Each scenario has always been revised several times before it could be considered as definitive. The basis of each story was the conflict situation in which clients really got in SH or elsewhere and whose solution turned out to be difficult for them. The main characters were people living in SH without the support of assistants. Unchanging character appearing in all scenarios was the "aggressor" - the person who creates a conflict situation. The characters were formed so that clients understood and could easily get an idea "what exactly is this man." The story has been put together into a few short images with short dialogues of the characters. For better orientation of clients during repetition in the FT workshop, each image had a specific name. Because the project was implemented in non-theatrical spaces of lounges in SH building, the emphasis was on familiarization of clients with topics of the story at the beginning of each production. It was the role of the Jokers. They were supposed to draw audiences - clients into action in adverse conditions. Even when practicing last modification of scenarios occurred.

II. Implementation phase - the implementation phase was crucial phase of the project, which should in practice prove or disprove the assumption that the workshop of Forum theatre is possible to realize with clients in sheltered housing. It contains two modules:

\section{Module 1. Preparation and training of theatre productions forum}

A series of preparatory meetings of the whole team were held before every premiere of a new FT staging, with the completion of details. An important step was the selection of the main characters for the stories, which should be the clients in situations difficult for them or almost unmanageable without the support of employees. A profile of the main characters was created on rehearsals (held mostly 1 week for 2.5 hours). Stories capture the frequent problematic situations of life in SH, which can stress the clients, sometimes even endanger their health or mental health, disrupt or alter their perception of the outside world, or can be seen as materially harm (fraud and manipulation). Analysis of the particular story characters are pointing to refine their characters and properties, based on discussions with SH employees. Story characters mirrored clients with their personality traits, which could also contribute to maximize drawing of the audiences - clients into the plot of the story. It was crucial to know the mentality of clients for the success of the work.

When shaping the final form of the production, improvisation techniques and tableaux, which help to accurate and more understandable expression of the core issue and to a clearer understanding of the relationships between the different actors, were used. Another significant figure that cannot be missing in FT performance is JOKER. Guide, facilitator, neutral advisor of FT, who accompanies the story. He also introduces the main character of the story to the viewers, activates the audience and has a lot of curious questions that leave the story open and unfinished. Knowledge of the clients and the ability to adapt their way of communication so that the performance for the audience - clients is clear 
and transparent is very important. A well-formulated Joker entry can additionally help to understand the context of the story and characters in a situation where, despite all the efforts of the authors, understanding of some passages cause problems for clients. The appropriate props are also important.

\section{Module 2 Productions Implementation}

The culmination of the project was the realization of individual productions.

- Project location: lounge of sheltered housing.

- Output Frequency: 1 production in two weeks (in the meantime the next staging was prepared altogether with a gradual evaluation of the project).

- Time and approximate duration of the workshop FT: 16:00 to 18:00. Participants in the project:

- Clients: 11, aged 25 to 58 years, including 7 women and 4 men. Students Actors: 7. Staff of sheltered housing: 4

Practical implementation of the FT with clients as audiences:

The whole team met at 15:30 am at the premises of performance. It was a common room connected to the dining room and kitchen. Dining room was used as an auditorium, living space as a stage. When preparing simple scene clients were coming. Along with them, the audience consisted of sheltered housing staff and students who did not take the part in the production. Actors and Jokers were ready in the second part of the lounge. 11 clients who were interested in joining the project attended the performance. The number of clients has not changed until the end of project. Opening belonged to jokers who acquainted the audience with the planned course of the meeting. The first point was to get acquainted with the actors - students with the help of the so-called warm-up techniques "Rozehřívaček" in a circle, which served for a relaxed atmosphere, and awakening a playful spirit. Customers were able to try what it's like to stand in the stage area. "Rozehřivačky" were taken from the book by A. Boal Games for Actors and Non-Actors and used at other meetings in different variations. At this moment, the audience already showed interest and curiosity. Jokers explained the course of the next steps in a simple and concise manner. They familiarize participants with the rules of FT. Followed by a practical demonstration involving spectators and workshops demonstration. Signal that audiences will be able to stop the action - clapping and saying the word "STOP" was arranged.

Jokers were illustrative of everything for better picture. There was even the space for questions. The majority of audience, however, stated that they want to see the theatre. Followed by the performance itself, where the complete story was played for the first time. Therefore viewers got familiar with it and had the opportunity to monitor solving of conflict situations, erroneous behaviour of the characters and inappropriate solution of the whole story. After the first play, two jokers entered the scene. They introduced the characters of the story to the viewers. Inquired the audience to find out what the story was about, whether they liked it, whether they were satisfied with how the story ended, and if they changed the behaviour of some characters. Viewers mustered the courage and started to be actively involved and began to play and alternate actor while 
entering roles. Each entry in the role of the character was accompanied by passing a significant object from the actor to the client. Another meeting with clients took place after a two-week break in the same place at the same time with the same group of clients. The course of FT was the same.

\section{Analysis and Interpretation of research results}

Qualitative research - Focus groups technique was chosen with regard to the target group with which the entire implementation forum theatre takes place. Since half of the clients have deficits in writing and reading, the questionnaire is not suitable method. Pros and cons were considered of other research methods and their possible applications to clients. Technique "Focusgoup" came out as the best one in obtaining the necessary data. This technique was chosen taking into consideration the already long-term cooperation with the target group and therefore its evaluation can be based on years of experience. Focus groups were conducted after each forum theatre workshop (hereafter FT) in the same room (lounge of sheltered housing), always with the same group of eleven clients who were present during the productions and workshops of FT. The whole course of the session was recorded with the recorder. "Focus" - the intention of all sessions based on research objectives. The aim of this method was to determine, whether people with mild and moderate mental retardation are able to understand the techniques and rules of FT. if they focus on the characters and stories of their roles and if the can identify the aggressor and be actively involved. Furthermore, if they are interested in topics and want to continue working with this technique. Evaluation of focus groups was conducted with the description and interpretation of subjective observation. In the following text, we will concentrate on the progress of the focus groups after individual workshops of FT (marked as: focus group - the name of the game).

\section{Focus group - BUCKET}

Group interviews showed that the clients in this game did not focus enough on roles. They could retell what someone did, what they saw and what the story was about. But clients did not recognize the central figure of Romana who was an aggressor - a client who caused the conflict with her inappropriate behaviour. Conversely, clients sympathized with this figure and, on the other hand, they negatively perceived the second protagonist Kate, as someone who makes trouble. Katka engaged clients' interest by her appearance, the actress had dreadlocks. She impressed them by her exotic appearance and her dominant character. But when interacting with her in a FT workshop, self-assertive clients were suddenly shy and timid. Understanding the story was distorted by clients. Authors' intention was to try different ways of solving simple conflicts of everyday life of clients. Given that it was the first clients' experience with FT and there was a participation of new people, clients did not focus, they were distracted and rules had to be constantly repeated.

\section{Focus group - A SHARP KNIFE}

During the interviews, it was found that clients are familiar with the characters of the story. They marginally defined the characters describing their properties. They identified the aggressor, because they disagreed with his 
treatment and he did not let anyone to give him a piece of advice. In this workshop they had trouble interfere the roles. They found it difficult to understand the difference between reality and play.

\section{Focus group - BULB}

During the interviews of focus groups after the workshop with the theme FT bulb, we could observe noticeably better orientation of clients in the story of FT and in its various stages. Clients even created their own name for the phase in FT with them in CHB. Production was named as a "show" and a workshop was renamed as "Cooking". For hosts, these interviews of focus groups were very revealing. They had the opportunity to look at FT with eyes of clients. Clients started talking about the characters and compared them with the people from their surrounding area. When asking about the characters they used this comparison and grabbed the story exactly according to our plan. It was interesting to watch how they perceive forum theatre.

\section{Focus group - DEALER}

Regarding the last focus group, we mainly wondered, whether clients were well informed with the FT rules. Clients surprised us in a pleasant way. Even the rule of clapping, which serves as a motivation for viewers entering into roles, was engaged. The hosts did not have to encourage clients with responses. The discussion was balanced. Clients have avoided the mockery and they were able to appreciate the other people more. They liked the dealer story. They described their personal encounters with such people and their attitude towards these people. As with FT workshop, also during the discussion, they had many ideas on how to avoid problems, but (surprisingly) they admitted with great selfcriticism that they were afraid of being taken in.

Quantitative Research - Quantitative research was conducted in a form of questionnaire. The questionnaire consisted of eight questions. Respondents were offered a choice of answers, or the addition to other opinion was possible for all the questions. Respondents consisted of 11 members of the implementation team of Forum theatre ( 7 Actors and 4 employees in direct care in sheltered housing). Thus, 11 questionnaires were distributed. The return was 100\%.

Question 1. Do you think that the theatre forum (hereafter FT) is beneficial for clients with mental retardation (hereinafter MR) and moderate mental retardation (hereinafter MMR)? Forum Theatre was beneficial for 9 clients $(81.2 \%)$ out of 11 respondents. $2(18.2 \%)$ respondents stated a different opinion with the following commentary: "The reason why the forum theatre was beneficial is that the clients acquainted with a different theatre technique. However, I saw the benefits of information I as questionable. "" For clients with mild mental retardation, yes, but it is necessary to consolidate the situation and continues in overplaying."

Question 2. Do you find the FT method useful when the social teachings of clients with MR and MMM? $8(81.8 \%)$ of 11 respondents believe that FT method is useful for clients. $1(9,1 \%)$ of respondents think that it is not usable, and $1(9,1 \%)$ has ambivalent views. 
Question 3. Do you assume that clients will be able to use their experience from DF in real life? $5(45,5 \%)$ of the 11 respondents assume that clients will be able to use the experience of FT in real life. The same number of respondents $(5 ; 45.5 \%)$ is not sure whether clients will be able to use the experience. $1(9 \%)$ of respondents believes that clients will be able to use experiences from the workshop.

Question 4. Do you think that clients understand the techniques DF? 4 (36, $4 \%$ ) of the 11 respondents believe that clients understood the techniques. 6 $(54.5 \%)$ of the respondents agreed that clients understood some techniques. 1 (9.1\%) respondents answered differently: "They did not understand the reason and consequences, they saw it as a form of play."

Question 5. Do you agree with the claim that FT provides space for employees, allowing them to attain more knowledge (new knowledge, information, facts) of clients? $10(90,9 \%)$ of the 11 respondents agreed that due FT employees can get to know the clients. $1(9,1 \%)$ respondent had a different opinion: "I do not know if this question concerns clients getting to know - in that case no. If the issue meant that clients learn something new yes."

Question 6. Do you agree with the claim that FT is a new way how clients can express their views and work with it? $8(72,7 \%)$ of the 11 respondents agreed with this statement. $3(27,3 \%)$ respondents stated a different opinion: "Clients just do not express their opinions so much in the FT. Probably only if they are the subject of direct concern and for example have their own experience with such a situation." "Thanks to this technique they are capable to express their opinion, I'm not sure about the relation to real life and further work with this issue." "it is only partially the new method. Overplaying model situations when it comes to e.g. a conflict followed by demonstration how they can this situation solve has already worked with clients." Last respondent probably did not understand the difference between FT and model situations where clients do not become involved in a situation and desired behaviour is only played.

Question 7. Do you think it is possible for FT methods to solve current problems and conflicts of clients? $10(90,9 \%)$ of respondents out of 11 think that it is possible to solve current problems and conflicts of clients with FT methods. $1(9,1 \%)$ of respondents says that he/she does not know.

Question 8. Do you think that the techniques of FT "entering into roles" and "resolution of conflict situations in the story" are understandable (to grasp) for clients? The respondents' answers for this question were diverse the most. $5(45,5 \%)$ of respondents think that technology "entering into roles" and "solution of the conflict in the story" is understandable for clients. $2(18,2 \%)$ of respondents disagree with this statement. $3(27.3 \%)$ of respondents are unsure. 1 (9, 1\%) of respondents stated a different opinion: "Especially for clients who are used to theatrical, dramatic work." 


\section{Discussions}

In the research, we have investigated whether clients with MR and MMM are able to understand the techniques and rules of FT:

- It was needed to repeat rules of FT due to clients' handicap each time before the realization

- For each subsequent implementation of the FT, which was held for two weeks, it was again necessary to repeat the rules.

- When entering into roles and independent decision making on the fate of the characters, clients were uncertain in their actions. They hid shame, stress and uncertainty behind comic resolution of the situation, which did not lead to an effective resolution of the situation. In this case, the character of the Joker, who in these moments uncritically conducted the workshops of FT and gave support to clients - viewers who responded positively to that assistance, has been proven.

The election of two Jokers was also proven useful. Knowing clients and their responses helped to discover the theatrical performing of clients in the role, who rather played for the audience and did not capture the actual changes in the storyline due to the overplaying their character. We also questioned whether clients are well informed about the characters - protagonists of the story and understand their roles, whether they can identify the aggressor.

- the focus groups, as well as observations revealed that clients of staged stories often favoured the dominant and vivid character with expressive behaviour that was represented in the story by the "aggressor" or the person who is the initiator of the conflict problematic situations.

- During one of the FT workshops, where the spectators in the audience always inclined to the side of the aggressor, in a discussion they advocated his actions, but after entering into the role they took the opposite stance, and therefore got into opposition with figure of aggressor.

- The aggressor, in this case, mirrored the pattern of behaviour that clients use in everyday life - thanks to the FT they had the opportunity of detachment.

Another area that we focused on was whether customers understood the plot, the dramatic situation in the story (understanding the intention of FT).

- From the discussions after the first play of the story it can be assumed that clients are partially informed. Due to their limited vocabulary, the assessment was curt, concise, i.e. One-word screams, that Jokers reacted on and tried to find out more.

- In the production of "bucket" the clients solved the aggressor's oppression, whom they perceived as a person who is in the right. The intention was to try with clients other ways of resolving conflict situations. At the first entry clients decided to resolve the situation with the same aggressive charge as an "aggressor".

- Client's support with the conflicted character of the story, with the "aggressor" can be also explained as they see temperament and dominant people as their idols. Many clients are submissive and this behaviour impresses them.

- Also there were effects of group dynamics, which always strongly influenced the opinion of the group - audience. Dramatic and grotesque behaviour of clients 
in FT workshops could be prevented by frequent and regular implementation of the FT in SH. We believe that the cause of excessive performing in front of an audience and consequently not grasping the role could be that clients have met with this alternative approach, which aims to develop their social skills for the first time. Therefore it has the "hallmark of novelty".

\section{Conclusions}

The aim of the research was to determine whether it is possible to implement Forum theatre for clients of sheltered housing with mild to moderate mental retardation. To realize the project of the Forum theatre with this target group was very challenging. Accomplishment of the intention lasted more than a year. FT realization with clients with MR and MMM is certainly possible, but given the diagnosis of the target group, it must be implemented in smaller time delays and for greater efficiency for this target group a long-term project will be needed altogether with the involvement of all direct care workers. It is very useful to involve as many people as possible, whose ideas and thoughts become part of the project and who thus aligns better with the result. Spontaneous participation and engagement is one of the most positive effects of FT and creates preconditions for its usefulness in the field of social learning and finding new ways of coping with stressful situations. Clients' need to discuss problems and try to solve them in a group was obvious during realization. Clients know theoretically where they make mistakes dealing with crisis situations, but they are not able to apply this knowledge in practice. And here FT may be beneficial. The Group has a large importance in sharing and mutual assistance and learning from conflicting interaction with others. Work through FT also gives the option to get to know and better understand the clients.

\section{References}

1. Boal, A. (1998). Legislativetheatre, 1.vyd., NewYork: Routledge

2. Čermáková, I. (1999). Augusto Boal a dramatická výchova. Tvořivádramatika, Praha: Artama

3. Hanzlíková, I. (2010). Realizace divadla fórum s klienty chráněného bydleni Domov Klič - CSS Olomouc, Olomouc, Diplomová práce, Univerzita Palackého v Olomouci, Fakulta Pedagogická, Katedra speciální pedagogiky, Vedoucí práce Mgr. Ph.D. Zdeňka Kozáková

4. http://fedifo.jamu.cz/terminologie.htm,cit.23.10.2015

5. Kozáková, Z. (2005). Psychopedie, Olomouc, Univerzita Palackého

6. Kozáková, Z. (2013). Special Education of Persons with Mental Disabilities. Olomouc: Univerzita Palackého

7. Macková, R. (2004). Divadlo Fórum v našich podmínkách. Gymnasion, Praha: PŠL

8. Morgan, D.L. (2001). Ohniskovéskupinyjakometodakvalitativního výzkumu, Boskovice: Nakladatelstvi Albert

9. Němec, J., Kusý, M. (1998). Aktivní sociální učení v podmínkách ústavní a ochranné výchovy, Praha

10. Uchytilová, B. (2003). Divadlo forum Augusta Boala. Tvořivá dramatika, Praha, Artama

11. Valenta, M., Kozáková, Z. (2006). Psychopedie 1 pro výchovné pracovníky. Olomouc: Univerzita Palackého 